\title{
Severe Respiratory Insufficiency Complicating Epstein-Barr Virus Infection: Case Report and Review
}

\author{
A. Haller, L. von Segesser, P. C. Baumann, \\ and M. Krause
}

From the Department of Internal Medicine and the Department of
Surgery (Heart and Vascular Surgery), University Hospital
of Zurich, Zurich, Switzerland

\begin{abstract}
We report a case involving a young adult who had life-threatening bilateral pneumonitis in the course of an acute Epstein-Barr virus (EBV) infection. Because of severe hypoxemia, the patient required mechanical ventilation and additional oxygenation by an intravascular oxygenator. The patient was treated with corticosteroids and survived without sequelae. Severe pulmonary involvement associated with EBV infection is a rare but potentially fatal complication of infectious mononucleosis. Similar cases reported in the literature are reviewed, and the therapeutic options for this particular complication are discussed.
\end{abstract}

Infectious mononucleosis is a worldwide, highly prevalent herpesvirus infection caused by Epstein-Barr virus (EBV). The disease is the result of a primary infection that occurs mostly early in life. During childhood, nonspecific symptoms or even a subclinical course prevail, whereas in adolescents the disease often leads to considerable morbidity [1]. Typically, the patients present with the triad of fever, pharyngitis, and lymphadenopathy, and splenomegaly is usually found on physical examination. Secondary immunologic responses are thought to play an important role in complicated courses, which may affect the heart, brain, and other organs [2, 3]. Severe clinical courses with complications requiring hospital treatment occur in merely $5 \%$ of the cases; however, only 100 fatal outcomes have been registered in the United States during a period of 10 years [4-6]. Case fatalities occur mainly in association with fulminant hepatitis, encephalitis, hemophagocytic syndrome, and splenic rupture [7-10].

Recently, we took care of a young, otherwise healthy adult who had life-threatening pneumonitis with severe hypoxemia in the course of an acute EBV infection. By exclusion of other causative agents, the pulmonary involvement was considered to be an EBV-related complication. Just a few similar cases have been reported in the literature; these are reviewed.

\section{Case Report}

In January 1994 a 30-year-old student at a police academy presented because of a 10-day history of fever, sore throat, swelling of the cervical lymph nodes, myalgias, and fatigue. He was seen by a physician, who prescribed a macrolide antibi-

Received 12 August 1994; revised 31 October 1994

Reprints or correspondence: Dr. M. Krause, Department of Internal Medicine, University Hospital of Zurich, Rämistrasse 100, CH-8091 Zürich, Switzerland.

Clinical Infectious Diseases 1995;21:206-9

(C) 1995 by The University of Chicago. All rights reserved.

$1058-4838 / 95 / 2101-0031 \$ 02.00$ otic that produced no improvement in the patient's condition. Cough and progressive dyspnea developed, and he was admitted to another hospital, where bilateral pneumonia with marked partial respiratory insufficiency (arterial partial pressure of oxygen $\left[\mathrm{PaO}_{2}\right], 5.32 \mathrm{kPa}$; arterial partial pressure of $\mathrm{CO}_{2}, 3.8 \mathrm{kPa}$; and arterial blood saturation with oxygen $\left[\mathrm{SaO}_{2}\right], 78 \%$ ) was diagnosed. Therapy with amoxicillin/clavulanic acid was begun. Because of progressive respiratory failure, the patient was intubated and mechanically ventilated. Hypoxemia persisted $\left(\mathrm{PaO}_{2}, 7.0 \mathrm{kPa}\right.$, despite an $\mathrm{FIO}_{2}$ of 1.0), and the patient was transferred to our hospital.

On admission, the patient was noted to have well-developed muscles. He was orally intubated. The pulse rate was 100 ; blood pressure, $140 / 80 \mathrm{~mm} \mathrm{Hg}$; and temperature, $37^{\circ} \mathrm{C}$. $\mathrm{He}$ appeared slightly cyanotic. No rash or lymphadenopathy was found. The pharynx was red and the tonsils were normal. Endinspiratory crackles were heard over both lungs. The liver was firm and enlarged, reaching $10 \mathrm{~cm}$ below the right costal margin. The spleen was palpable $3 \mathrm{~cm}$ below the left costal margin. The remaining examination findings were unremarkable.

The chest roentgenogram obtained on the day of admission showed bilateral diffuse, confluent infiltrates, particularly in the middle and lower fields (figure 1A). The electrocardiographic findings were normal. The hemoglobin level was $11 \mathrm{~g} / \mathrm{dL}$, and the leukocyte count was $8.4 \times 10^{3} / \mu \mathrm{L}$, with $40 \%$ lymphocytes (more than one-half of which were atypical $[23 \%$ of leukocytes]). The following other values were noted: C-reactive protein, $156 \mathrm{mg} / \mathrm{dL}$ (normal, $<10 \mathrm{mg} / \mathrm{dL}$ ); total protein, 41 $\mathrm{g} / \mathrm{L}(65-79 \mathrm{~g} / \mathrm{L})$; bilirubin, $32 \mu \mathrm{mol} / \mathrm{L}(<22 \mu \mathrm{mol} / \mathrm{L})$; serum aspartate aminotransferase, $193 \mathrm{U} / \mathrm{L}(<60 \mathrm{U} / \mathrm{L})$; serum alanine aminotransferase, $193 \mathrm{U} / \mathrm{L}(<60 \mathrm{U} / \mathrm{L})$; creatine kinase, 316 $\mathrm{U} / \mathrm{L}(<50 \mathrm{U} / \mathrm{L})$; and lactic dehydrogenase, $911 \mathrm{U} / \mathrm{L}(230-460$ $\mathrm{U} / \mathrm{L}$ ). The lactate, creatinine, and coagulation parameters were normal. Ultrasonography of the abdomen confirmed hepatosplenomegaly but disclosed no other pathological findings. Examination of the scarce tracheal aspirate revealed very few cells and no bacteria on a gram stain.

A pulmonary catheter was inserted, revealing high cardiac output and a normal pulmonary capillary wedge pressure. Intra- 

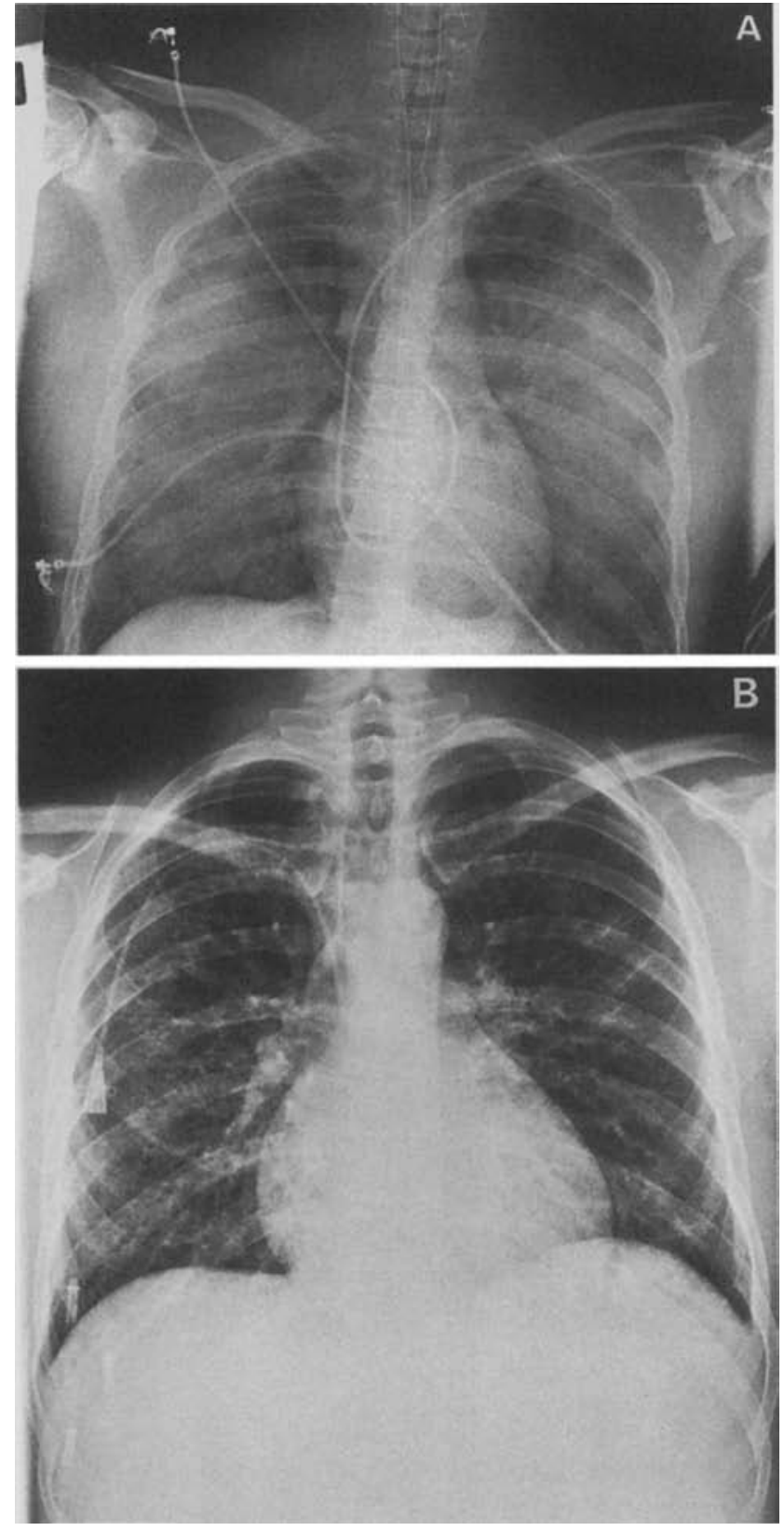

Figure 1. $A$, Chest roentgenogram obtained on admission, showing intense, diffuse bilateral infiltrates without pleural effusion. $B$, Chest roentgenogram obtained 2 days before discharge, showing significant resolution of the pulmonary infiltrates.

venous therapy with amoxicillin/clavulanic acid was continued, and erythromycin was added to the regimen. In addition, a corticosteroid regimen was begun $(100 \mathrm{mg}$ of prednisone daily). Arterial blood gas measurements showed continuous marked hypoxemia $\left(\mathrm{PaO}_{2}, 6.5 \mathrm{kPa} ; \mathrm{SaO}_{2}, 68 \%\right)$ despite an $\mathrm{FlO}_{2}$ of 1.0 and a positive end-expiratory pressure of 10 mbar. An intravascular oxygenator was implanted through a section in the right femoral vein. Over the next 10 hours, central venous and arterial oxygenation improved markedly; 36 hours later, the respiratory situation had significantly improved, and the intravascular oxygenator was removed. Four days after admission, a macular-papular exanthema was observed on the trunk. Four days later, amoxicillin/clavulanic acid and erythromycin were withdrawn and therapy with vancomycin and ceftazidime was begun because of a catheter-related infection due to coagulase-negative staphylococci. After a total of 11 days of mechanical ventilation, the patient was extubated and the steroid doses were tapered.

All blood cultures and cultures of tracheal aspirates remained negative. Serological tests disclosed the following findings: heterophil antibodies (monospot test), positive; EBV viral capsid antigen IgM, positive; EBV viral capsid antigen IgG titer, 1:1,280; EBV nuclear antigen, negative; EBV early antigen (D and R) IgG titer, 1:160; cytomegalovirus (CMV) IgG, negative; and CMV IgM, questionably positive. Both the EBV and CMV serologies were performed by two independent laboratories and yielded the same results. Serological tests for Mycoplasma pneumoniae, Legionella pneumophila, Q-fever, Brucella species, Chlamydia species, influenza A and B viruses, parainfluenza 1 and 2 viruses, adenovirus, picornavirus (echovirus, coxsackievirus), and measles virus (all by complement fixation) and for HIV and respiratory syncytial virus (by ELISA) were negative, including control tests performed 2 weeks later. Sixteen days after admission the patient was discharged from the hospital. He was in good condition and has resumed his training at the police academy. A chest roentgenogram obtained at the time of discharge is shown in figure $1 \mathrm{~B}$.

\section{Discussion}

This patient presented many classical features of infectious mononucleosis, including the signs at initial presentation (fever, pharyngitis, cervical lymphadenopathy, abnormal lymphocyte counts, and elevated liver enzyme levels), the rash that developed during aminopenicillin therapy, and a positive EBV serology. The severe pulmonary involvement in the course of his acute EBV infection, however, is an unusual complication that is rarely reported. The negative bacterial cultures and serological tests made a diagnosis of coinfection with a second agent unlikely. Furthermore, noninfectious causes (including acute respiratory distress syndrome and cardiac pulmonary edema) were excluded on the bases of normal lung compliance during mechanical ventilation, absence of productive proteinrich lung secretions, and normal cardiac performance values. There was no evidence that this patient had an underlying immunological defect predisposing to a severe course of primary EBV infection.

In systematic radiographic studies of infectious mononucleosis, pulmonary involvement is detectable in $5 \%-10 \%$ of the cases [11]. However, these findings appear to be clinically insignificant, since discrete pulmonary symptoms may be neglected because of other, predominant EBV-related symptoms. We have found in the literature descriptions of 12 immunocom- 
Table 1. Characteristics of previously reported cases of EBV infection with symptomatic lung involvement.

\begin{tabular}{|c|c|c|c|c|}
\hline $1[12]$ & $48 / \mathrm{M}$ & + & Bilateral diffuse infiltrates, mediastinal lymphadenopathy & Recovery \\
\hline $2[13]$ & $21 / \mathrm{M}$ & NS & Peribronchial infiltrates & Recovery \\
\hline $3[14]$ & $17 / \mathrm{M}$ & + & Diffuse interstitial infiltrates, right-sided pleural effusions & Death, ARDS* \\
\hline $4[14]$ & $22 / \mathrm{M}$ & + & Diffuse patchy infiltrates & Recovery \\
\hline $7[16]$ & $17 / \mathrm{F}$ & NS & Diffuse bilateral patchy infiltrates & Recovery \\
\hline $8[17]$ & $4 / F$ & NS & Bilateral interstitial infiltrates & Recovery \\
\hline $9[18]$ & $48 / \mathrm{M}$ & + & Bilateral interstitial infiltrates & Recovery* \\
\hline $10[19]$ & $18 / \mathrm{M}$ & NS & Right-sided pleural effusion & Recovery \\
\hline $11[20]$ & $22 / \mathrm{M}$ & NS & Bilateral infiltrates, pleural effusion & Recovery \\
\hline $12[21]$ & $16 / \mathrm{F}$ & + & Diffuse pulmonary infiltrates & Recovery \\
\hline
\end{tabular}

NOTE. $\quad$ ARDS $=$ acute respiratory distress syndrome; $\mathrm{NS}=$ not specified $++=$ positive.

* Patients 3 and 9 were supported by mechanical ventilation.

petent patients with acute EBV infection who had symptomatic lung involvement (table 1). Significant hypoxemia was documented in 5 patients; 2 required mechanical ventilation and 1 died of pulmonary failure. The radiologic examinations revealed diffuse interstitial infiltrates, which occur unilaterally or bilaterally and may show concomitant pleural effusions. In one case, lung tissue was examined histologically [12]. Mononuclear infiltrations were found predominantly in the perivascular and peribronchial tissues and were also detected in the intraalveolar septa. These findings, however, did not differ from the findings in other cases of viral pneumonia.

Clinically, severe hypoxemia appears to be a predominant feature of EBV-related pneumonitis. In our case, mechanical ventilation did not increase blood oxygen saturation sufficiently, a circumstance that encouraged us to advocate oxygenation by means of implantation of an intravascular gas exchanger. The beneficial role of such devices has not been established, although it appears that they have contributed significantly to survival in individual cases $[22,23]$. Although blood oxygenation improved markedly following implantation of the intravascular oxygenator in our patient, it cannot be excluded that the rapid improvement occurred spontaneously or was the result of corticosteroid therapy.

The role of corticosteroids in treatment of acute EBV infections is still controversial. Controlled studies of uncomplicated cases of mononucleosis showed no clinical benefit [24]; however, for cases involving complications that are believed to be secondary immunopathological reactions (such as hemolytic anemia, encephalitis, and myocarditis), the administration of steroids has been recommended. It remains unclear whether pulmonary involvement in EBV infections is the result of direct viral invasion of lung tissue or whether it represents an immunological reaction. Our experience with the case presented herein would encourage us to use steroids again in the treatment of severe EBV-related pneumonitis.

\section{Acknowledgment}

The authors thank Mrs. H. Boeschenstein-Manner for translation of the text.

\section{References}

1. Hoagland RJ. The clinical manifestations of infectious mononucleosis: a report of two hundred cases. Am J Med Sci 1960;240:21-9.

2. Hoffman GS, Franck WA. Infectious mononucleosis, autoimmunity and vasculitis: a case report. JAMA 1979;241:2735-6.

3. Purtilo DT. Immunopathology of infectious mononucleosis and other complications of Epstein-Barr virus infections. Pathol Annu 1980; 15:25399.

4. McCurdy JA Jr. Life-threatening complications of infectious mononucleosis. Laryngoscope 1975;85:1557-63.

5. Fisher M, Shenker IR, Nussbaum MP. Infectious mononucleosis: review of complications in hospitalized series. N Y State J Med 1980;80:92934.

6. Penman HG. Fatal infectious mononucleosis: a critical review. J Clin Pathol 1970;23:765-71.

7. Harries JT, Ferguson AW. Fatal infectious mononucleosis with liver failure in two sisters. Arch Dis Child 1968;43:480-5.

8. Grose C, Henle W, Henle G, Feorino PM. Primary Epstein-Barr-virus infection in acute neurologic diseases. N Engl J Med 1975;292:392-5.

9. Kikuta H, Sakiyama Y, Matsumoto S, et al. Fatal Epstein-Barr virusassociated hemophagocytic syndrome. Blood 1993;82:3259-64.

10. Safran D. Spontaneous splenic rupture following infectious mononucleosis. Am Surg 1990;58:601-5.

11. Lander P, Palayew MJ. Infectious mononucleosis-a review of chest roentgenographic manifestations. J Can Assoc Radiol 1974;25:303-6.

12. Myers JL, Peiper SC, Katzenstein AL. Pulmonary involvement in infectious mononucleosis: histopathologic features and detection of EpsteinBarr virus-related DNA sequences. Mod Pathol 1989;2:444-8.

13. Rodstein M. A case of infectious mononucleosis with atypical pneumonia. Ann Intern Med 1948;28:1177-87.

14. Offit PA, Fleisher GR, Koven NL, Plotkin SA. Severe Epstein-Barr virus pulmonary involvement. J Adolesc Health Care 1981;2:121-5.

15. Mundy GR. Infectious mononucleosis with pulmonary parenchymal involvement. Br Med J 1972;1:219-20.

16. Andiman WA, McCarthy P, Markowitz RI, Cormier D, Horstmann DM. Clinical, virologic, and serologic evidence of Epstein-Ban virus in- 
fection in association with childhood pneumonia. J Pediatr 1981;99: 880-6.

17. Fermaglich DR. Pulmonary involvement in infectious mononucleosis. J Pediatr 1975;86:93-5.

18. Veal CF Jr, Carr MB, Briggs DD Jr. Diffuse pneumonia and acute respiratory failure due to infectious mononucleosis in a middle-aged adult. Am Rev Respir Dis 1990; 141:502-4.

19. Eaton OM, Little PF, Silver HM. Infectious mononucleosis with pleural effusion. Arch Intern Med 1965; 115:87-9.

20. Vander JB. Pleural effusion in infectious mononucleosis. Ann Intern Med 1954;41:146-51.
21. O'Donohue WJ, Polly SM, Angelillo VA. Diffuse pneumonia and acute respiratory failure due to infectious mononucleosis. Nebr Med J 1981;66:245-7.

22. Gentilello LM, Jurkovich GJ, Gubler KD, Anardi DM, Heiskell R. The intravascular oxygenator (IVOX): preliminary results of new means of performing extrapulmonary gas exchange. J Trauma 1993; 35:399--404.

23. von Segesser LK, Schaffner A, Stocker R, et al. Extended (29 days) use of intravascular gas exchange [letter]. Lancet 1992;339:1536.

24. Collins M, Fleisher G, Kreisberg J, Fager S. Role of steroids in the treatment of infectious mononucleosis in the ambulatory college student. I Am Coll Health 1984; 33:101-5. 